\title{
A Predictive Control Strategy for Power Factor Correction
}

\author{
P.Kripakaran ${ }^{1}$, J.Sathishkumar ${ }^{2,}$ R.Gopi Krishna ${ }^{3}$ \\ ${ }^{I}$ (Department of EEE, Rajiv Gandhi College of Engineering and Technology, India) \\ ${ }^{2}$ (Department of EEE, Rajiv Gandhi College of Engineering and Technology, India) \\ ${ }^{3}$ (Department of EEE, Rajiv Gandhi College of Engineering and Technology, India)
}

\begin{abstract}
Harmonic pollution and low power factor in power systems caused by power converters have been a great concern. To overcome these problems several converter topologies and control schemes have been proposed in recent years. This paper is proposed to study the control techniques for such converters to improve the Power Factor (PF) and reduce total harmonic distortion (THD) in the input current with output voltage regulation. A new predictive control strategy for boost PFC is presented in this paper. Its basic idea is that all of the duty cycles required to achieve unity power factor in a half line period are generated by using predictive control. The duty cycle is determined based on the input voltage, reference output voltage, inductor current, and reference current. The proposed PFC control is derived based on Boost converter operates at continuous conduction mode and the switching frequency is much higher than the line frequency so that input voltage can be assumed as a constant during one switching cycle.
\end{abstract}

Keywords: Power Factor Correction, Total Harmonic Distortion, Boost Converter, Predictive Control

\section{Introduction}

In most power electronic applications, the power input is of 50 or 60 hertz $\mathrm{AC}$ voltage provided by the electric utility. It further converted to a DC voltage for various applications [3]. The inexpensive rectifiers with diodes convert AC to DC and the output voltage is uncontrolled. The controlled rectifiers are used for providing variable/ constant output voltage. The dc output voltage of a controlled/uncontrolled rectifier should be ripple free [2]. Therefore a large capacitor is connected as a filter on dc side. Due to this, controlled/uncontrolled rectifier has the following drawbacks. These rectifiers draw highly distorted current from the utility .Power factor is very low. In high power rectifiers Switch mode AC-DC converters are being used as front end rectifiers for variety of applications due to the advantage of high efficiency and power density [4]. These switched mode ac to dc converters, also draw non sinusoidal input current with low power factor and high harmonics content. This has led to the consistent research to improve the performance of various conversion system and hence new topologies for switch mode power factor corrected AC to DC converter. The switch mode power factor corrected AC to DC converter has been in two directions namely, buck and boost type topologies [5]. The advantage of Buck type topology is that converter can provide variable output voltage, which is lower than the input voltage. However when the instantaneous input voltage is below the output voltage the current drops to zero, and the results in significant increase in THD of the input current [9]. The boost type converter is capable of producing the output dc voltage which is higher than the input ac voltage. The input current in these converters flows through the boost inductor which helps to wave shape using appropriate current control strategies. Hence boost converters not only provide regulated dc output voltage but also maintained near unity power factor and reduce THD of the input current [6]. The boost type converters with various topologies have found wide spread use in various applications due to its advantages such as high efficiency, high power density and inherent power quality improvement at input and output [10].

\section{Current Control Techniques For Pfc Converters}

The current control techniques have gained importance in ac to dc converters used for high performance applications, where the fast response and high accuracy are important. Various current control methods have been proposed and classified as hysteresis control, predictive control and linear control. Principle of these methods are briefly described and discussed below.

\subsection{HYSTERESIS CONTROL}

Hysteresis current control is an instantaneous feedback control system which uses the current error when exceeds the limit of the band, the switches are turned on/off. The advantage of this technique is simple, accurate, and robust. Also, the speed of the response is limited by switching speed of the device and time constant of the load. The variable switching frequency operation is considered as the only disadvantage. 


\subsection{LINEAR CONTROL}

In the linear control scheme, the actual currents are compared to the references and the errors are processed by conventional proportional-integral controllers to provide a reference control signal for a PWM modulator. This produces constant-frequency with pulse width-modulated gate signals for the converter switches. The controller parameters are adjusted to optimize the system transient response. The implementation of linear controller is relatively straightforward using standard integrated circuits.

\section{Boost Converter Topology Based Ac To Dc Converter}

The boost converter topology is used for controlling the output and input performance. Various current control strategies have been applied. The input current is maintained sinusoidal with unity power factor. The output voltage of AC to DC converter is regulated and maintained. The operation and controller implementation is discussed below to achieve the said performance.

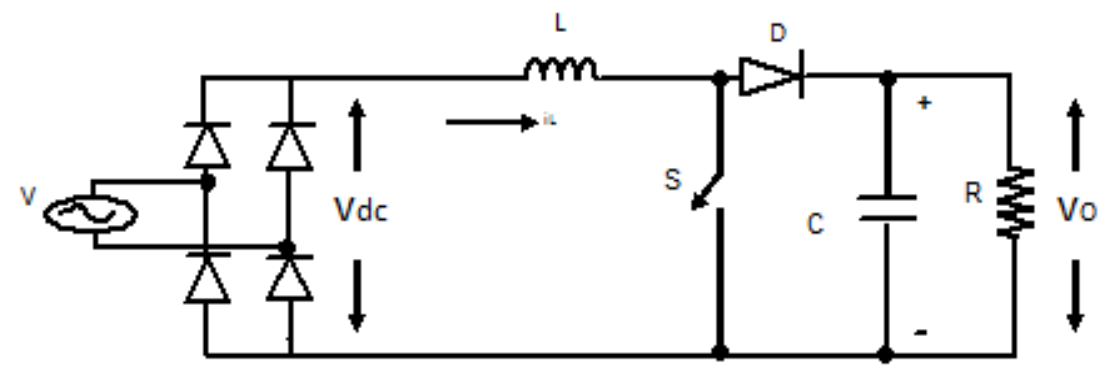

Fig 1: Boost converter topology

Figure 1. Shows a single phase AC to DC converter, where a single-phase diode bridge and a following single ended boost converter are employed. An inductor $\mathrm{L}$ called the boost inductor is connected in series as shown in Fig. 1 the output capacitor $\mathrm{C}$ is connected in parallel to the load R reduces the ripple in the output voltage. By controlling the switch $\mathrm{S}$, appropriately, the input current and output voltage are maintained at a desirable value and shape. The boost converter operates in two modes, which are mode ON and mode OFF. During mode ON, the switch S is in on state and hence, the diode is reverse biased. In this mode, source is short through L, Diode Bridge and switch S. As a result, the current in the inductor L increases. During mode off S is turned off. The diode D is forward biased. The source is connected to the capacitor $\mathrm{C}$ through bridge, the inductor $\mathrm{L}$ and the Diode $\mathrm{D}$. As a result, the inductor current $\left(\mathrm{i}_{\mathrm{L}}\right)$ decreases. The output voltage $\left(\mathrm{V}_{\mathrm{o}}\right)$ gets increased and will become more than the $\mathrm{V}_{\mathrm{dc}}$.

This topology is cost effective due to single control switch. The number of conducting devices is three, i.e. the switch (s) and two diodes of the bridge conduct. The reverse recovery property of the diodes produces high switching losses and results in low efficiency.

\subsection{DESIGN OF R, L, C}

For the given specification of the converter, procedure to design the value of $\mathrm{R}, \mathrm{L}$, and $\mathrm{C}$ is as follows. In general, current ripple is considered for designing the value of inductance L. Voltage ripple is considered for designing the value of capacitance $\mathrm{C}$.

The maximum ripple current $\left[\mathrm{I}_{\text {rip max }}\right]$ for this converter is given as

$$
\mathrm{I}_{\text {rip } \max }=\frac{V}{4 f_{s} L}
$$

Where

$$
\begin{aligned}
& \text { V- Output voltage } \\
& \mathrm{f}_{\mathrm{s}} \text { - Switching frequency }
\end{aligned}
$$$$
\text { Let } \mathrm{I}_{\text {rip } \max }=1 \mathrm{~A}
$$

Substituting this in eqn (1) the value of the inductance has been calculated as

$$
\begin{aligned}
L & =\frac{100}{4 X .1 X 160000} \\
& =1.5 \mathrm{MH}
\end{aligned}
$$

The voltage ripple $\left(\mathrm{V}_{\text {ripple }}\right)$ for this converter is given as 


$$
\mathrm{V}_{\text {ripple }}=\frac{I}{2 \omega C}
$$

Where
I- Output current
C-Capacitance

The output current I can be calculated as $\mathrm{I}=\frac{\text { outputpower }}{\text { outputvoltage }}$

$$
\begin{aligned}
I & =100 / 100 \\
& =1 \mathrm{Amps}
\end{aligned}
$$

Let $\mathrm{V}_{\text {ripple }}=0.8$ volts

Substituting $\mathrm{V}_{\text {ripple }}$ and I in eqn (2) the value of $\mathrm{C}$ has been calculated as follows.

$$
\begin{aligned}
\text { C } & =\frac{1}{2 X 2 \Pi X 50 \times .8} \\
& =2 \mathrm{mF}
\end{aligned}
$$

\section{V. Closed Loop Operation Of Boost Converter Topology With Predictive Control}

The predictive control [1] predicts the current-error-vector at the beginning of each modulation period. The prediction is based on the error and the load variables. The predicted voltage vector is used by the PWM pulse generator during the next modulation cycle and hence minimizes the error. This technique uses more information along with regulator error signal and hence produces accurate output response from the converters. The predictive regulators are particularly suitable for digital implementation. Where the signal acquisition can be discrete and suitable for implementation in digital which may provide good calculation power needed for effective control of the converter operation and improve the performance.

The closed loop arrangement of the boost converter based ac to dc converter topology with predictive control is shown in Figure 2 presented as follows.

The switch voltage reference $\left(\mathrm{V}_{\mathrm{sw} \text { ref }}\right)$ at $(\mathrm{k}+1)^{\text {th }}$ instant is predicted at $\mathrm{k}^{\text {th }}$ instant itself for the circuit shown in Figure (2) by means of eqn (4).

$$
\begin{aligned}
& \mathrm{V}_{\mathrm{sw} \text { ref }}(\mathrm{k})=\mathrm{V}_{\mathrm{d}}(\mathrm{k})-\mathrm{L}\left\{\mathrm{i}_{\mathrm{d}}\left(\mathrm{t}_{\mathrm{k}+1}\right)-\mathrm{i}_{\mathrm{d}}\left(\mathrm{t}_{\mathrm{k}}\right)\right\} / \mathrm{T} \\
& \text { Where } \\
& \mathrm{V}_{\mathrm{d}}-\text { rectified voltage } \\
& \mathrm{i}_{\mathrm{d}} \quad-\text { inductor current } \\
& \mathrm{T} \quad \text { - Modulation period (inverse of switching frequency) }
\end{aligned}
$$

To implement the eqn (4) all the parameters at the $\mathrm{k}^{\text {th }}$ instant can easily be sensed, expect the current $\mathrm{i}_{\mathrm{d}}$ at $(\mathrm{k}+1)^{\text {th }}$ instant. For that the reference signal $\mathrm{i}_{\mathrm{d}}{ }^{*}$ which has been derived from the rectified voltage as shown in Figure 2 has been phase shifted by a modulation period of $\left(t_{(K+1)}-t_{K}\right)$ and it has been used in the eqn (4) as $i_{d}^{*}(k+1)$ instead of $i_{d}(k+1)$. So the control law has been modified as eqn (5)

$$
\mathrm{V}_{\mathrm{sw} \text { ref }}(\mathrm{k})=\mathrm{V}_{\mathrm{d}}(\mathrm{k})-\mathrm{L}\left\{\mathrm{i}_{\mathrm{d}}{ }^{*}\left(\mathrm{t}_{\mathrm{k}+1}\right)-\mathrm{i}_{\mathrm{d}}\left(\mathrm{t}_{\mathrm{k}}\right)\right\} / \mathrm{T}
$$

Since the switching frequency is very high the modulation period is very small. The current $i_{d}$ at $(k+1)$ th instant will be approximately equal to the current id at $\mathrm{k}^{\text {th }}$ instant. So the eqn no (5) is modified to (6)

$$
\mathrm{V}_{\mathrm{sw} \mathrm{ref}}(\mathrm{K})=\mathrm{V}_{\mathrm{d}}(\mathrm{k})-\mathrm{L}\left\{\mathrm{i}_{\mathrm{d}}{ }^{*}\left(\mathrm{t}_{\mathrm{k}}\right)-\mathrm{i}_{\mathrm{d}}\left(\mathrm{t}_{\mathrm{k}}\right)\right\} / \mathrm{T}
$$




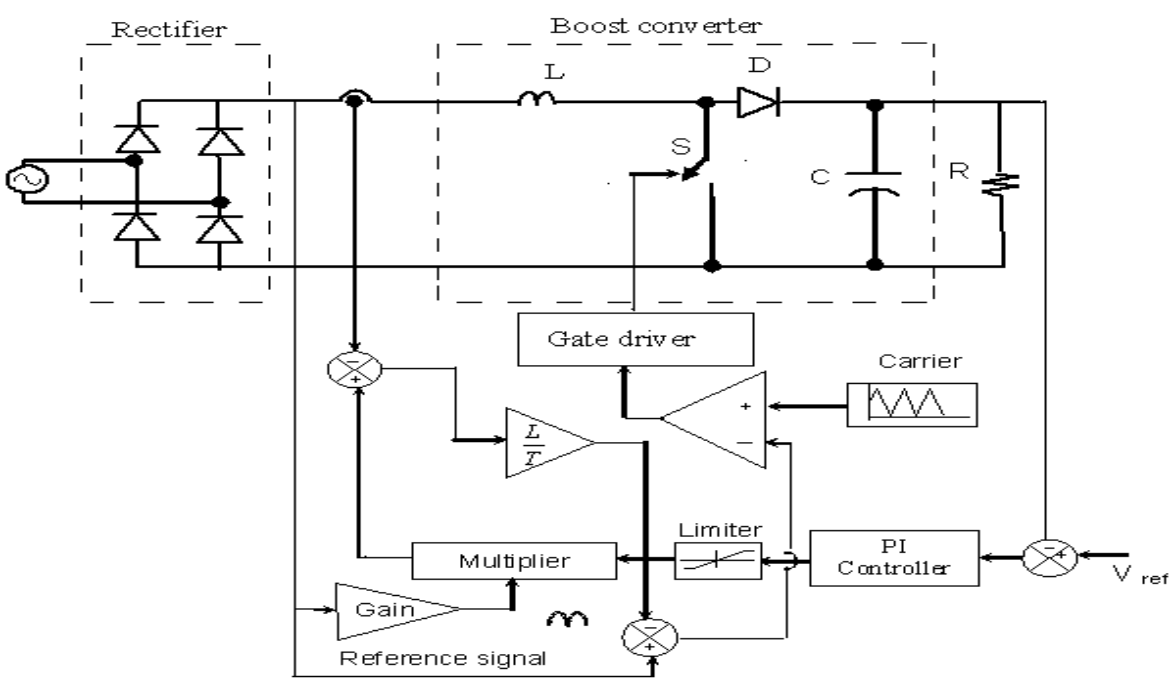

Fig: 2 Boost converters with predictive control

The same control law has been written in Analog domain as eqn (6). It is implemented in the circuit shown in Fig. 2 to obtain the reference switch voltage $\left(\mathrm{V}_{\mathrm{sw} \text { ref }}\right)$.

$$
\mathrm{V}_{\mathrm{sw}} \operatorname{ref}(\mathrm{t})=\mathrm{V}_{\mathrm{d}}(\mathrm{t})-\mathrm{L}\left\{\mathrm{i}_{\mathrm{d}}{ }^{*}(\mathrm{t})-\mathrm{id}(\mathrm{t})\right\} / \mathrm{T}
$$

The reference switch voltage is compared with the carrier whose amplitude is varying according to the load voltage and it is given to the switch S. The operation of the switch results in Sinusoidal current and unity power factor. PI-controller has been used externally to regulate the output voltage.

\section{Simulation Results And Analysis}

The boost converter with predictive control discussed in the previous session is validated for the following parameters using MATLAB / SIMULINK Software as shown in fig 3.

\subsection{SPECIFICATIONS OF CONVERTER USED}

The boost converter based ac to dc converter has been simulated with the following specifications. .

\begin{tabular}{|l|l|}
\hline Source voltage & 55 Volts (rms) \\
\hline Output voltage & 100 Volts (avg) \\
\hline Output power & $100 \mathrm{~W}$ \\
\hline Switching frequency & $160 \mathrm{KHz}$ \\
\hline Line current THD & $\leq 5 \%$ \\
\hline Inductance & $1.5 \mathrm{MH}$ \\
\hline Capacitance & $2 \mathrm{mC}$ \\
\hline
\end{tabular}

Table 1: Specification of Converter Used

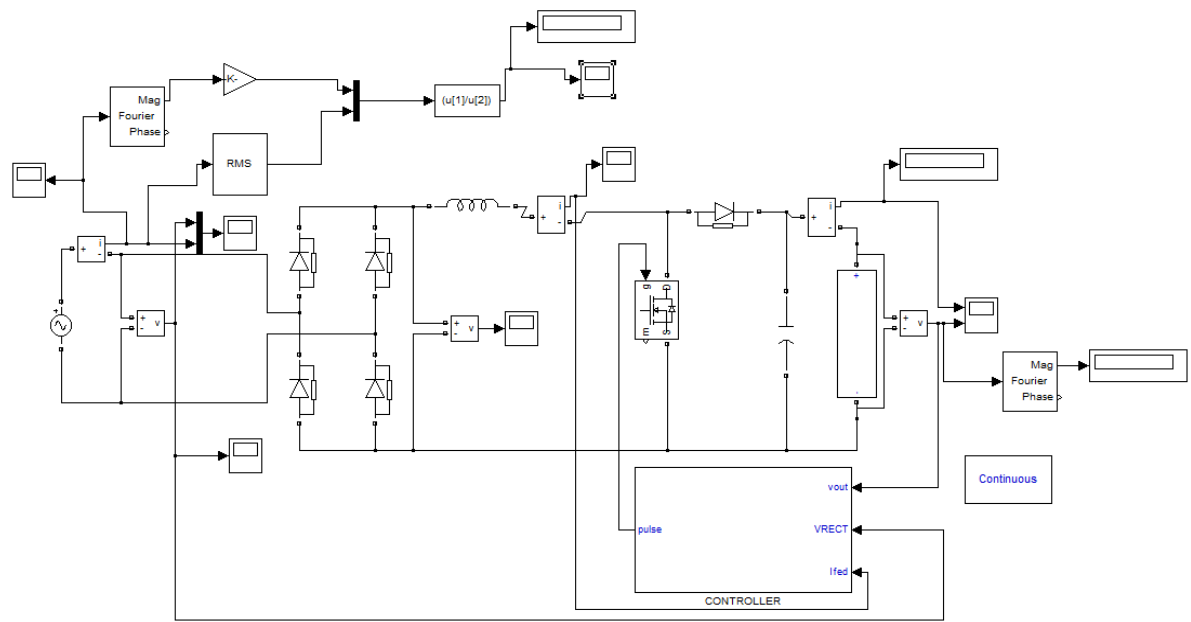

Fig: 3 Simulation Circuit of Boost Converter with Predictive Control 


\subsection{SIMULATION RESULTS}

The simulation results for the various cases are listed below.

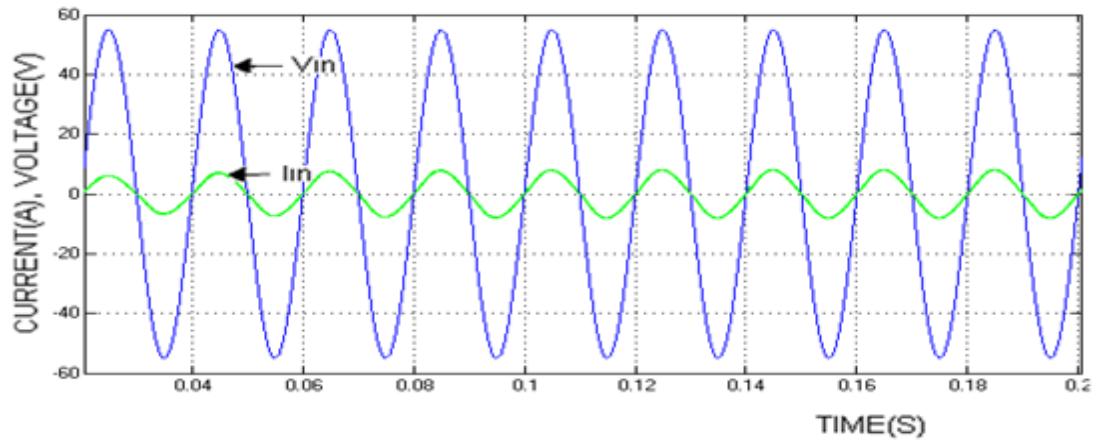

Fig 4: Input Voltage and Current Waveform at Full Load
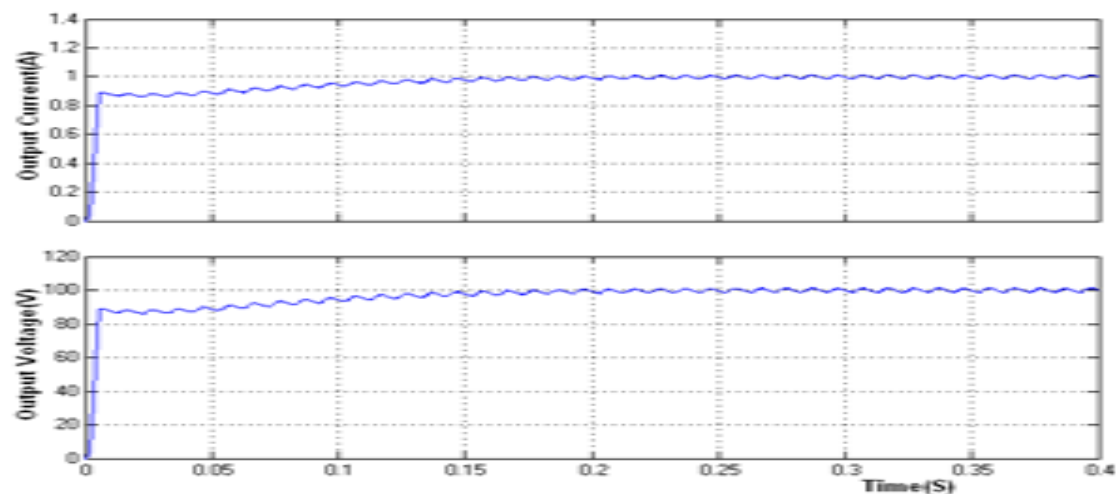

Fig 5: Output Current and Voltage at Full Load

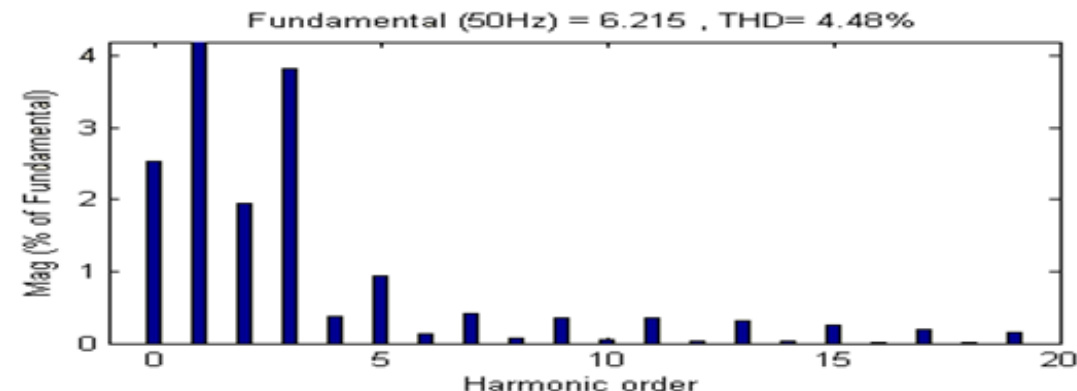

Fig 6: Harmonic Spectrum of input current at Full Load

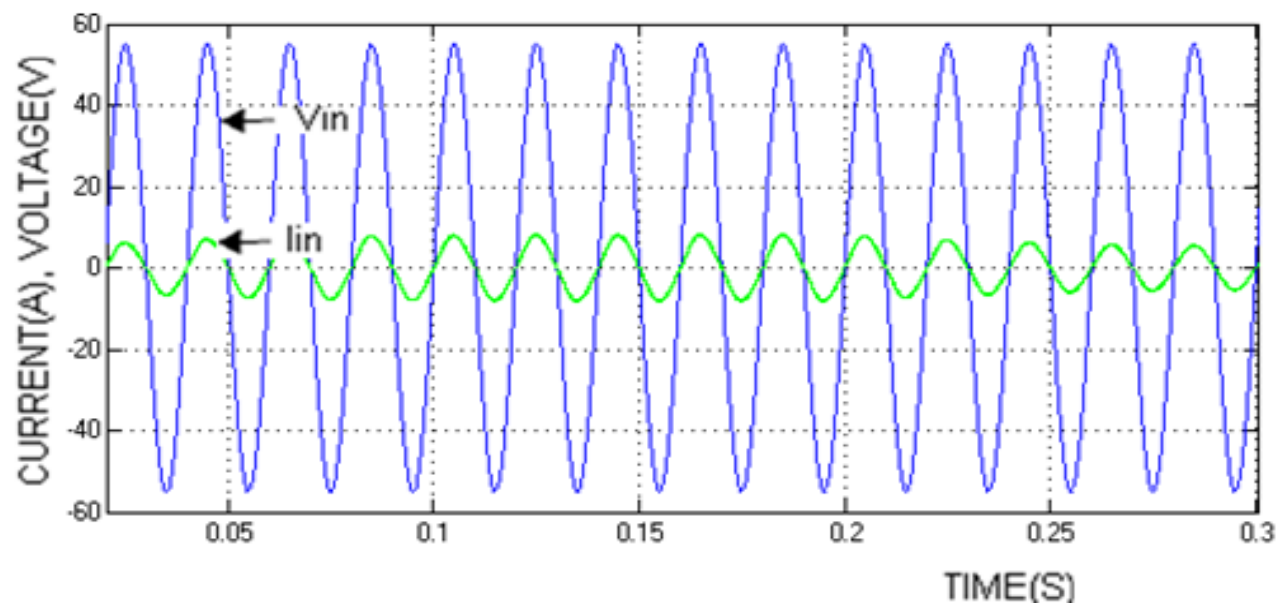

Fig 7: Input Voltage and Current Waveform at Different Load 

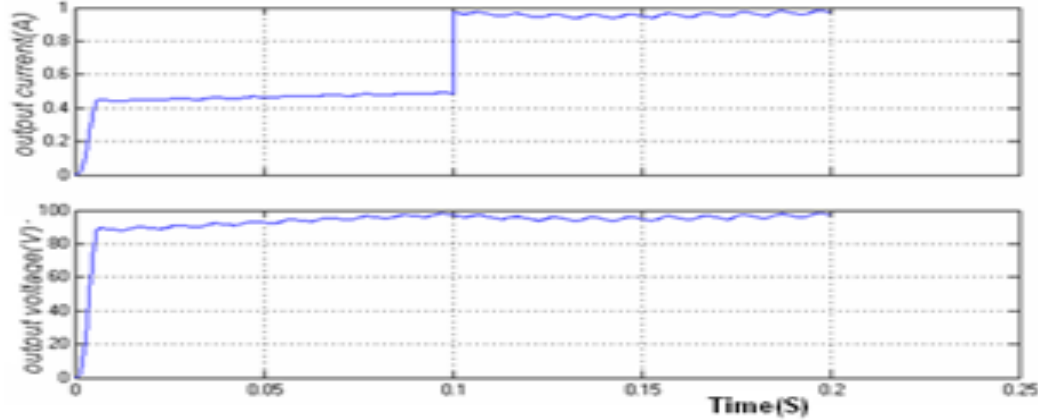

Fig 8: Output Current and Voltage at Different Load

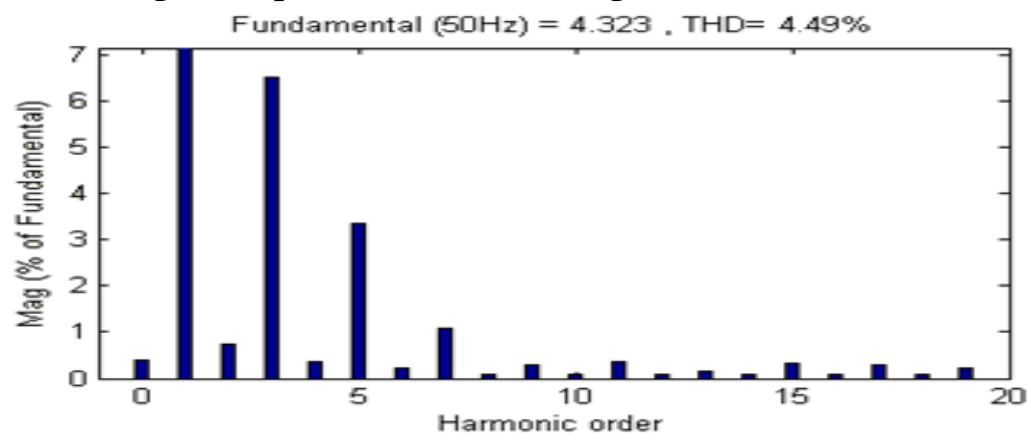

Fig 9: Harmonic Spectrum of input current at Full Load

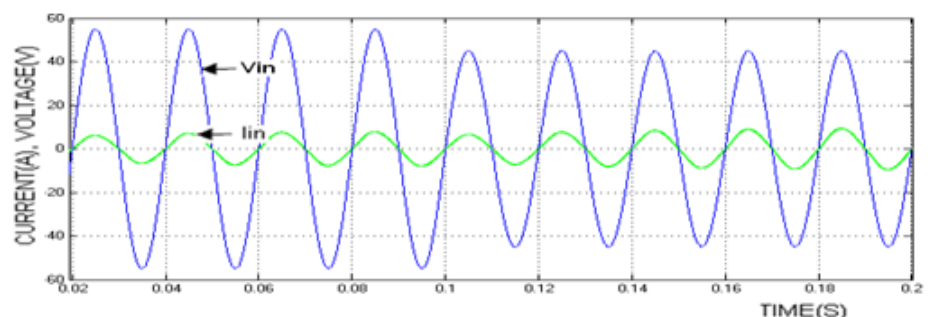

Fig 10: Input Voltage and Current Waveform at Distorted Input
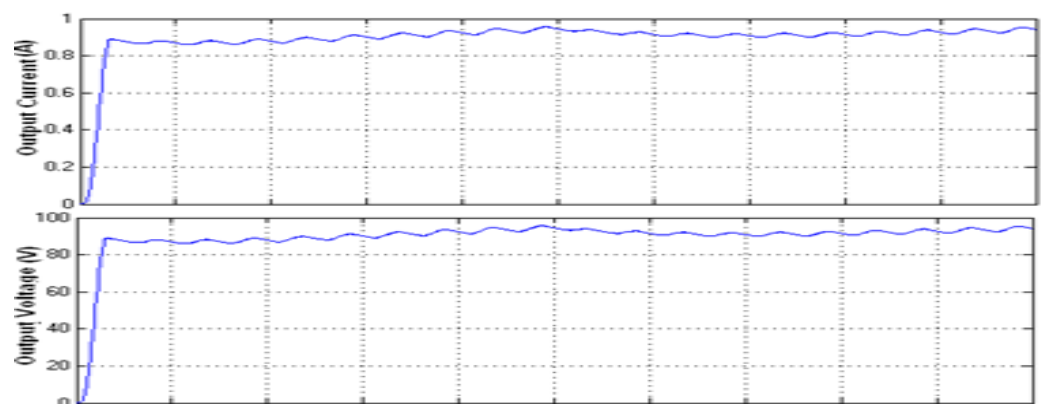

Fig 11: Output Current and Voltage at Distorted Input

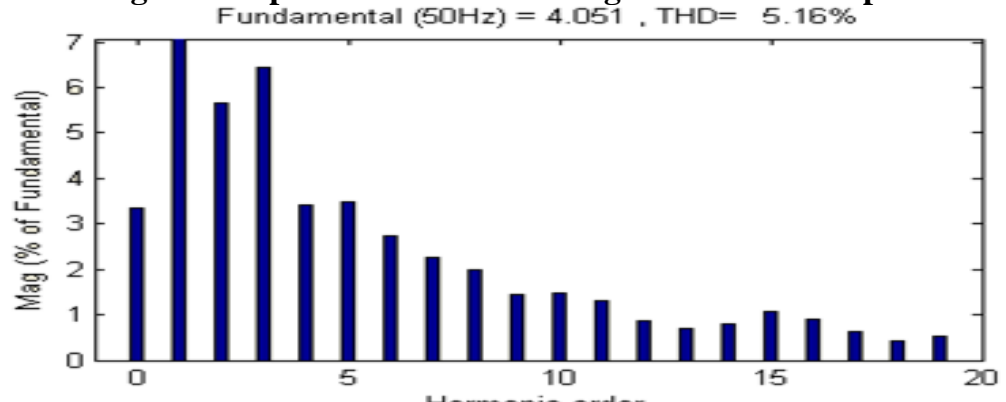

Fig 12: Harmonic Spectrum of input current at Distorted Input 
A Predictive Control Strategy For Power Factor Correction

\begin{tabular}{|c|c|c|c|}
\hline Case & $\begin{array}{c}\text { Output Voltage } \\
\text { (Volts) }\end{array}$ & Power Factor & $\begin{array}{c}\text { \% Total Harmonic } \\
\text { Distortion }\end{array}$ \\
\hline Full Load & 100 & 0.997 & 4.48 \\
\hline Different load & 99.5 & 0.992 & 4.49 \\
\hline Input Distortion & 99.5 & 0.998 & 5.12 \\
\hline
\end{tabular}

Table 2: Output Voltage, Power Factor and THD for Different Cases

\section{Conclusion}

Closed loop performance of PFC converters with predictive control scheme have been studied and verified through simulation. Simulation results show that the proposed strategy works well and close to unity power factor can be achieved over wide input voltage and load variation. The proposed PFC control strategy can achieve sinusoidal current waveform in the transient state for step load change and input voltage change. It has been observed that power factor is maintained near unity (0.99), THD in input current is $\leq 5 \%$. Output voltage is maintained constant to $100 \mathrm{~V}$ irrespective of the load variation as well as supply voltage variation.

\section{References}

[1] Wanfeng Zhang, Guang Feng, Yan-Fei Liu and Bin Wu, "A Digital Power Factor Correction (PFC) Control Strategy Optimized for DSP, ” IEEE TRANSACTIONS ON POWER ELECTRONICS, VOL. 19, NO. 6, NOVEMBER 2011

[2] Fariborz Musavi, Murray Edington, Member, Wilson Eberle and William G. Dunford, "Control Loop Design for a PFC Boost Converter With Ripple Steering," IEEE TRANSACTIONS ON INDUSTRY APPLICATIONS, VOL. $49, \quad$ NO. 1 , JANUARY/FEBRUARY 2013.

[3] R. Redl and B. P. Erisman, "Reducing distortion in peak-current-controlled Boost power-factor correctors," in Proc. IEEE Applied Power Electronics Conf. Expo, 1994, pp. 576-583.

[4] Sungsik Park and Sewan Choi, "Soft-Switched CCM Boost Converters With High Voltage Gain for High-Power Applications" IEEE TRANSACTIONS ON POWER ELECTRONICS, VOL. 25, NO. 5, MAY 2010

[5] R. Zane and D. Maksimovic, "Nonlinear-carrier control for high-power factor rectifiers based on up-down switching converters," IEEE Trans Power Electron., vol. 13, pp. 213-221, Mar. 1998.

[6] S. Buso et al., "Simple digital control improving dynamic performance of power factor pre-regulators," IEEE Trans. Power Electron., vol. 13, pp. 814-823, Sept. 1998.

[7] S. Bibian and H. Jin, "Digital control with improved performance for Boost power factor correction circuits," in Proc. 16th Annи. IEEE Applied Power Electronics Conf. Expo, 2001, pp. 137-143.

[8] S. Kim and P. N. Enjeti, "Control of multiple single phase PFC modules with a single low-cost DSP," in Proc. 18th Annu. IEEE Applied Power Electronics Conf. Expo, vol. 1, 2003, pp. 375-381.

[9] J. Chen, A. Prodic, R. W. Erickson, and D. Maksimovic, "Predictive digital current programmed control," IEEE Trans. Power Electron., vol. 18, pp. 411-419, Jan. 2003.

[10] W. Merfert, "Stored-duty-ratio control for power factor correction," in Proc. IEEE Applied Power Electronics Conf. Expo, vol. 2 , 1999, pp.1123-1129. 